\title{
Ambient Noise Tomography for a High-resolution 3D S- Wave Velocity Model of the Kinki Region, Southwestern Japan, using Dense Seismic Array Data
}

BOKANI NTHABA ( $\sim$ bokanin@mine.kyushu-u.ac.jp )

Kyushu University - Ito Campus: Kyushu Daigaku https://orcid.org/0000-0002-0341-049X

\section{Tatsunori Ikeda}

Kyushu University - Ito Campus: Kyushu Daigaku

Hiro Nimiya

National Institute of Advanced Industrial Science and Technology Geological Survey of Japan: Sangyo Gijutsu Sogo Kenkyujo Chishitsu Chosa Sogo Center

\section{Takeshi Tsuji}

Kyushu University - Ito Campus: Kyushu Daigaku https://orcid.org/0000-0003-0951-4596

\section{Yoshihisa lio}

Disaster Prevention Research Institute Kyoto University

\section{Research Article}

Keywords: Ambient Noise Tomography, S-wave velocity model, Niigata-Kobe Tectonic Zone, Kinki region, Zerocrossing method, Surface waves

Posted Date: February 2nd, 2022

DOI: https://doi.org/10.21203/rs.3.rs-1294028/v1

License: @ (i) This work is licensed under a Creative Commons Attribution 4.0 International License. Read Full License 


\section{Abstract}

Research interest in the Kinki region, southwestern Japan, has been aroused by the frequent occurrence of microearthquake activity that do not always coincide with documented active fault locations. Previous studies in the Kinki region focused mainly on deep, large-scale structures and could not efficiently resolve fine-scale ( 10 $\mathrm{km}$ ) shallow crustal structures. Hence, characterization of the upper crustal structure of this region at an improved spatial resolution is required. From the cross-correlation of the vertical components of the ambient seismic noise data recorded by a densely-distributed seismic array, we estimated Rayleigh wave phase velocities using a frequency domain method. Then, we applied a direct surface wave tomographic method for the measured phase velocity dispersion data to obtain the 3D S-wave velocity model of the Kinki region. The estimated velocity model reveals a NE-SW trending low-velocity structure coinciding with the Niigata-Kobe Tectonic Zone (NKTZ) and the active Biwako-seigan Fault Zone (BSFZ). Also, we identified fine-scale lowvelocity structures coinciding with known active faults on the eastern side of the NKTZ, as well as sets of lowvelocity structures across the Tanba region, that may be attributable to the weathering effects or activity of unidentified concealed fault zones. Furthermore, sedimentary basins manifest as low-velocity zones extending to depths ranging from $\sim 1.5$ to $2 \mathrm{~km}$, correlating with those reported in previous studies. Our results therefore contribute towards fundamental understanding of earthquake faulting as well as tectonic boundary and will be useful for hazard assessment and disaster mitigation.

\section{Introduction}

To unravel heterogeneities within the crustal structure and upper mantle over a wide area, very few geophysical techniques with proven efficacy are available (Suemoto et al. 2020). Active-source geophysical techniques such as seismic reflection and refraction can be used to map and characterize geological structures at high resolution. A striking example is a study by Sato et al. (2009), in which deep seismic reflection profiling was employed to reveal several active reverse faults along a 135-km-long Osaka-Suzuka seismic profile. Likewise, Ito et al. (2006) conducted a similar survey along the N-S-trending Shingu-Maizuru line. However, this approach only provides details about fault locations and geologic boundaries along the profiles, and heterogeneities across the profiles can only be established from multiple profiles. Therefore, this approach is not well suited to constructing large-scale geological models for areas as large as the Kinki region.

Conversely, P- and S-wave travel-time tomography utilizing earthquake data over a wide area has provided significant results, resolving major structures such as faults and geologic boundaries (Matsubara et al. 2008; Nakajima et al. 2009; Yolsal-Cevikbilen et al. 2012). Even so, the downside of this approach is that the resolution of geological structures depends on the distribution of natural earthquakes (Suemoto et al. 2020). Using teleseismic data, surface wave tomography can also be applied. However, due to the occurrence of attenuation and scattering as distant waves propagate, teleseismic propagation paths complicate short period (<20 s) measurements (Bensen et al. 2007; Yang 2014). Such short-period measurements are the core of our objectives in this study as we seek to resolve shallow crustal features within the Kinki region.

The emergence of ambient noise tomography (ANT) in recent years has transformed seismic tomography because it can circumvent the shortcomings of traditional earthquake surface wave tomography (Sabra et al. 2005; Shapiro et al. 2005). The ANT method utilizes ambient noise to extract surface wave Green's functions between pairs of seismic stations by cross-correlating continuous seismic waveforms recorded at those stations 
(Yang 2014). In this method, surface wave dispersion data between pairs of seismic stations can be estimated

in the absence of earthquakes because each station can operate as a virtual source and a receiver (Yang 2014). Since the inception and further developments of permanent and temporary high-quality seismic networks, ANT has been successfully utilized to delineate subsurface geologic features in various geological settings (Chen et al. 2018; Lin et al. 2008; Nishida et al. 2008; Shapiro et al. 2005). Suemoto et al. (2020) applied ambient noise surface wave tomography to estimate a high-resolution 3D S-wave velocity structure of the San-in area using continuously recorded seismic waveforms by a seismic network comprising Hi-net stations (Obara et al. 2005) and the Manten project array (lio et al. 2018). Similarly, Nimiya et al. (2020) successfully utilized continuously recorded ambient noise data by Hi-net stations to construct the 3D S-wave velocity model of central Japan. In contrast, information about the shallow-crustal S-wave velocity structure of the Kinki region is limited.

In our study, we applied ambient noise tomographic inversion to provide an improved constraint on fine-scale ( 10 km) shallow-crustal structures and geological boundaries in the Kinki region. A high-resolution shallow Swave velocity model was estimated using data recorded by the widely distributed permanent and temporary seismic stations. From our model, the geometry and spatial distribution of major faults and geological boundaries are estimated.

\section{Geologic Setting}

In the Kinki region, southwestern Japan, the Eurasian (EUR) plate overrides the subducting Philippine Sea (PHS) oceanic plate (Aoki et al. 2016). The southeastward movement of the incipient Amurian plate (Amur Plate) with respect to the EUR plate and a shift in the subduction direction of the PHS plate (Taira 2001) has generated relatively new, large fault zones or continually reactivates the old ones, a process referred to as neotectonics (Barnes 2008).

The major contributors in neotectonics faulting in the Kinki region comprise, among others, the reactivated Median Tectonic Line (MTL; black line in Fig. 1a), which has a right-lateral strike-slip fault movement (Barnes 2008). The MTL divides the Kinki region into outer zone and inner zone (Matsushita 1963). On the one hand, the outer zone is characterized by four zonally arranged terrains from north to south: namely, the Sanbagawa metamorphic terrain, Chichibu terrain, Hidaka terrain, and Muro terrain (SMZ, CT, HT, and MT; Fig. 1a). On the other hand, the zonal arrangement of geologic formations in the inner zone is not prominent, and it is characterized by the Neogene volcanic and sedimentary series of the Tango-Tajima terrain (TTT), the Yakuno intrusive rocks and marine formations of the Maizuru zone (MZ), Cretaceous granites of the Mino-Tanba terrain (MTT), and metamorphic and granitic rocks of the Ryoke terrain (RT; Fig. 1a) (Matsushita 1963).

Huzita (1980) delineated a triangular-shaped neotectonics zone characterized by the E-W compression in the upper crust and undulating topography of alternating sedimentary basins and mountain ranges, called the Kinki triangle (gray-shaded area in Fig. 1a). This tectonic zone provided Kinki region with its civilizational homelands, including the Osaka, Nara, Kyoto and Ise basins (Barnes 2008). The Kinki triangle is characterized by numerous Quaternary active faults predominantly oriented in the N-S direction and some NE-SW or NW-SE strike-slip faults (Research Group for Active Faults of Japan 1991). A plethora of historical large and destructive earthquakes have occurred in the Kinki region and surrounding areas (Hyodo and Hirahara 2003; Usami 2003), especially in the western side of the Kinki triangle (Tanba region; Wakita 2013), bounded by the ENE-WSW strike-slip Arima-Takatsuki Tectonic Line (ATTL) to the south (Hallo et al. 2019; lio 1996; Katao et al. 1997; 
Matsushita and Imanishi 2015) and the reactivated Niigata-Kobe Tectonic Zone (NKTZ) to the east (Sagiya et al. 2000). In recent times, low magnitude earthquakes have been recorded across the entire Tanba region, but their locations do not always coincide with known faults (Kato and Ueda 2019). Despite this discrepacy, some of the earthquake hypocenters in the Tanba region are aligned in the same direction as known faults, whereas some of are linearly distributed between pairs of known faults (Oike 1976). The chain of seismic alignment in this region suggests the possible existence of concealed active faults in those areas, or continuity of known fault systems. Therefore, the possible existence of concealed faults in those areas needs to be investigated in high resolution.

Around the Osaka area, numerous strike-slip and reverse active faults of diverse orientations exist (Research Group for Active Faults of Japan 1991). The significance of these faults was highlighted by the highly catastrophic $1995 \mathrm{M}_{\mathrm{w}} 7.2$ Kobe earthquake, which resulted from the strike-slip displacements on the RokkoActive Fault Zone (Kanamori 1995; Katao et al. 1997). In addition, a shallow crustal earthquake of $M_{w} 5.6$ occurred in 2018, proximal to the zone of intersection between the ATTL, the Uemachi and Ikoma fault zones (Kato and Ueda 2019; Sato et al. 2009). These earthquakes are a testament to how susceptible life is to displacements along these fault zones and highlight the need to identify zones prone to strong crustal movement in a quest to minimize the effects of destructive earthquakes. Such zones include concealed fault zones, which are difficult to ascertain from surficial evidence, as well as active and new fault systems, which are likely to be the locus of future events.

\section{Data And Methods}

We utilized the vertical component of continuously recorded seismic waveforms by permanent and temporary stations from April 1 to September 30 during the year 2019. The permanent stations included 78 Hi-net stations, 1 Kyushu University station, 1 Tokyo University station, 2 Nagoya University stations, 10 AIST stations, 16 Kyoto University stations and 9 JMA stations, and temporary stations comprised 104 Kyoto University Manten project stations (lio et al. 2018; Katoh et al. 2019), that are distributed around the central part of the Kinki region. Combining these set of stations enabled us to obtain a dataset with adequate short-period surface waves ray paths coverage and a subsequent 3D S-wave velocity model of high-resolution. Firstly, we computed the crosscorrelation of ambient noise to extract surface waves propagating between pairs of seismic stations. We then estimated Rayleigh wave phase velocity measurements between station pairs using the zero-crossing method (Ekström et al. 2009). Finally, we constructed the shallow crustal 3D S-wave velocity structure by applying the direct surface wave inversion method (Fang et al. 2015).

\section{Preprocessing and cross-correlation}

After partitioning daily seismic waveforms into 30 -minute-long segments with a $50 \%$ overlap, we eliminated the instrumental response of each dataset. Next, cross-correlation spectra for all the paired seismic stations were computed from the resulting seismograms (Ekström 2014). Then, the daily cross-correlation spectra were stacked over a six-month-long time series. The time-domain cross-correlations computed from stacked crosscorrelation spectra clearly shows the Rayleigh wave propagation between station pairs (Fig. 2).

\section{Surface wave phase velocity measurements}


Phase velocity measurements can be conducted in either the time domain or frequency domain. The time domain analysis requires the high-frequency approximation and only considers those interstation distances exceeding three wavelengths $(\lambda)$ (Bensen et al. 2007; Lin et al. 2008; Yao et al. 2006). In contrast, the frequency domain approach has no theoretical limitation for interstation distances (i.e., zero-crossing method; Ekström et al. 2009). As such, interstation distances up to approximately one wavelength can be practically used (Ekström et al. 2009; Tsai and Moschetti 2010). In our study, we used the zero-crossing method to derive phase velocity measurements between station pairs. This method is based on modeling cross-correlation spectra by the spatial autocorrelation (SPAC) method (Aki 1957; Asten 2006) and uses the zero-crossing frequencies of the real part of the cross-correlation spectra. The SPAC method is premised on the assumption that ambient noise sources are homogeneously distributed and that ambient noise is predominantly surface waves (Aki 1957). Under this assumption, a Bessel function of the first kind and zeroth order can be used to model the real part of the vertical cross-correlation spectra as follows:

$\operatorname{Real}(\rho(f, x))=J_{0}\left(\frac{2 \pi f x}{C_{R}(f)}\right)$,

where $\rho$ is the cross-spectrum, $f$ is the frequency, $x$ represents the interstation distance, $J_{0}$ represents the Bessel function of the first kind and zeroth order, and $C_{R}(f)$ represents the Rayleigh wave phase velocity. In the zerocrossing method, we only focus on the zero crossing points where both sides of Eq. (1) should be zero. The zerocrossing points are not sensitive to fluctuations in the power spectrum of the background noise and non-linear filtering in the data processing (Ekström et al. 2009). Using zero crossings simplifies phase velocity measurements and stabilizes the estimation of phase velocities because phase velocity estimation is not affected by incoherent noise (Cho et al. 2021).

If $f_{\mathrm{n}}$ represents the frequency of the observed $n$th zero crossing point of the cross-correlation spectrum, and $Z_{n}$ denotes the $n$th zero of the Bessel function, we can match each $f_{\mathrm{n}}$ with the zero crossing points of the Bessel function to have all the possible phase velocity dispersion curves according to the following equation:

$$
C_{m}\left(f_{n}\right)=\frac{2 \Pi f_{n^{X}}}{Z_{n+2 m}},
$$

2

where $m$ representing the number of missed or additional zero crossing points, takes the values $(0, \pm 1, \pm 2, \ldots)$. Applying Eq. (2) for all observed values of $f_{\mathrm{n}}$ yields numerous possible dispersion curves.

We used the GSpecDisp package (Sadeghisorkhani et al. 2018) to estimate phase-velocity dispersion curves uniquely by the zero-crossing method from the stacked cross-correlations. To reduce noise effects in the correlations, we applied a velocity filter of $1-4.5 \mathrm{~km} / \mathrm{s}$ with a taper interval of $\sim 0.2 \mathrm{~km} / \mathrm{s}$. Then, we applied spectral whitening to each correlation for amplitude equalization (Sadeghisorkhani et al. 2018). With many possible phase velocities occurring at each frequency with regard to Eq. (2) (colored dots; Fig. 3a), it is difficult to uniquely determine the phase velocity dispersion curves without using a reference velocity dispersion curve as a guide. To circumvent this, we manually picked the dispersion curve appearing closest to the reference dispersion curve. In the GSpecDisp, average velocities can be estimated by combining all cross-correlation spectra (average velocity module). We estimated average velocities in the period range from 2 to $8 \mathrm{~s}$ and used the result as a 
reference velocity for dispersion curve estimation in single station-pair phase-velocity picking mode in GSpecDisp (dashed black dots; Fig. 3a). Finally, we estimated phase-velocity dispersion curves between all the possible station pairs (red circles in Fig. 3a).

For our dataset, the maximum measurable period required an interstation distance $(\mathrm{x}, \mathrm{in} \mathrm{km})$ of at least three wavelengths $(\lambda)$, defined as the $r / \lambda$ ratio in GSpecDisp $(x / \lambda \geq 3)$. For each cross-correlation function, the signalto-noise ratio (SNR) was defined as the ratio between maximum absolute amplitude in the signal window (between arrival times corresponding to waves with 1 and $4.5 \mathrm{~km} / \mathrm{s}$ ) and the root mean square amplitude in the noise time window (between 500 and $700 \mathrm{~s}$ ). We used an SNR threshold of 10 to reject correlations with low signal. Finally, we obtained a total of 23,647 dispersion curves (Fig. 3c).

\section{Direct inversion of the surface wave dispersion curves}

Ambient noise tomography using phase velocity dispersion curves typically involves a two-step procedure. Firstly, 2D phase velocity maps are constructed by travel-time tomography at discrete frequencies. Secondly, pointwise inversion of dispersion data for 1D profiles of S-wave velocity as a function of depth at each grid point is implemented, and combining multiple 1D profiles subsequently yields the 3D S-wave velocity structure (Shapiro and Ritzwoller 2002; Yao et al. 2008). Nonetheless, a 3D S-wave velocity structure can equally be estimated by direct inversion of dispersion data without the intermediate step of constructing 2D phase velocity maps (Boschi and Ekström 2002; Fang et al. 2015; Feng and An 2010; Pilz et al. 2012). Typically, these direct inversion approaches do not update the ray paths and sensitivity kernels for the newly constructed 3D models (Fang et al. 2015). Also, one-step linearization may produce biased wave velocity estimations in a medium akin to the shallow crustal structure, where S-wave velocity variations can exceed 20\% (Lin et al. 2013).

To estimate the 3D S-wave velocity structure from phase velocity dispersion data, we applied a direct surface wave tomography method (DSurfTomo), which is based on frequency-dependent ray-tracing and a waveletbased sparsity-constrained inversion (Fang et al. 2015). This approach circumvents the intermediate step of constructing 2D phase velocity maps and iteratively updates the sensitivity kernels of period-dependent dispersion data (Fang et al. 2015). Furthermore, it accounts for the ray-bending effects of period-dependent ray paths by using the fast-marching method (Rawlinson and Sambridge 2004). Accounting for such effects in the inversion is especially useful for short-period surface waves, which are significantly sensitive to the highly complex shallow crustal structure (Fang et al. 2015; Gu et al. 2019). Therefore, this approach is a well-suited tool for determining the shallow-crustal structure of the Kinki region using short-period surface-waves dispersion data.

In tomographic inversion, the objective is to find a model $\mathbf{m}$ that minimizes the differences $\delta t_{i}(f)$ between the measured travel times $t_{i}^{o b s}(f)$ and the calculated travel times $t_{i}(f)$ from the model for all frequencies $f$. The travel time for path $i$ is given as

$$
\delta t_{i}(f)=t_{i}^{o b s}(f)-t_{i}(f) \approx-\sum_{k=1}^{K} v_{i k} \frac{\delta C_{k}(f)}{C_{k}^{2}(f)},
$$


where $t_{i}(f)$ represents the computed travel times from a reference model which can be updated during the inversion, $v_{i k}$ denotes the bilinear interpolation coefficients along the ray path associated with the ith travel-time data, $C_{k}(f)$ is the phase velocity and its perturbation $\delta C_{k}(f)$ at the $k$-th two-dimensional surface grid node at frequency $f$ (Fang et al. 2015). Surface wave dispersion is primarily sensitive to S-wave velocity. However, shortperiod Rayleigh wave dispersion is also sensitive to the compressional (P-wave) velocity in the shallow crustal structure (Fang et al. 2015). The P-wave velocity perturbations together with mass density are therefore explicitly included in the calculation of surface wave dispersion, with $R_{\alpha}^{\prime}$ and $R_{\rho}^{\prime}$ as scaling factors, leading to the following equation:

$\delta t_{i}(f)=\left.\sum_{k=1}^{K}\left(-\frac{V_{i k}}{C_{k}^{2}}\right) \sum_{j=1}^{J}\left[R_{\alpha}^{\prime}\left(z_{j}\right) \frac{\partial C_{k}}{\partial \alpha_{k}\left(z_{j}\right)}+R_{\rho}^{\prime}\left(z_{j}\right) \frac{\partial C_{k}}{\partial \rho_{k}\left(z_{j}\right)}+\frac{\partial C_{k}}{\partial \beta_{k}\left(z_{j}\right)}\right]\right|_{\theta_{k}} \delta \beta_{k}\left(z_{j}\right)=\sum_{l=1}^{M} G_{i l} m_{l}$

where $\theta_{k}$ denotes the one-dimensional (1D) reference model at the $k$-th surface grid node, $\alpha_{k}\left(z_{j}\right), \rho_{k}\left(z_{j}\right)$, and $\beta_{k}\left(z_{j}\right)$ represent the P-wave velocity, the mass density, and the S-wave velocity, respectively. $J$ indicates the number of grid points in the depth direction, and $M=K J$ represents a sum of all the model grid points. Equation (4) can be written as follows:

$\mathbf{d}=\mathrm{Gm},(5)$

where $\mathbf{d}, \mathbf{G}$, and $\mathbf{m}$ represent the surface wave travel-time residual vector for all ray paths and discrete frequencies, data sensitivity matrix, and the model parameter vector, respectively. We applied the damping and weighting parameters are applied to balance data fitting and smoothing regularization. In addition to the damping and weighting parameters, the sparsity fraction, which is a parameter indicating how sparse the sensitivity matrix is, was selected on a trial-and-error basis for our data considering the diverse patterns in inverted S-wave velocity models (weakly smoothed and strongly smoothed S-wave velocity models are shown in Figures S1 and S2, respectively).

In our inversion, the entire Kinki region was parameterized into 55 by 60 grid points on the horizontal plane with $0.05^{\circ}$ intervals between grid points in each horizontal direction, as well as 7 grid points along the depth direction (i.e., 0, 0.5, 1.0, 2.2, 4.0, 6.0 and $9.0 \mathrm{~km}$ ). These parameters along with the large volume of dispersion data were memory intensive, we therefore used dispersion data within a narrow frequency bandwidth of $0.083-0.67 \mathrm{~Hz}$ to circumvent the computer memory limitations during the inversion. Dispersion measurements within a broad frequency bandwidth of $0.05-0.95 \mathrm{~Hz}$ was used for the northern part of the Kinki area, which was parameterized into 29 by 96 grid points on the horizontal plane with $0.02^{\circ}$ grid point intervals in the latitude and longitude directions, and 11 grid points along the veritical direction $(0,0.1,0.3,0.5,0.8,1.4,2.0,3.0,4.0,5.5$ and $7.0 \mathrm{~km})$. Empirically, the fundamental mode Rayleigh wave phase velocity is primarily sensitive to $1.1 \times$ S-wave velocity at a depth of about 1/3 multiplied by its corresponding wavelength $(\lambda$ ) (Fang et al. 2015; Foti et al. 2014; Hayashi 2008). Consequently, we averaged the observed Rayleigh wave phase velocities at depths of about $1 / 3 \lambda$ and then multiplied them by 1.1 to construct and initial S-wave velocity model of the study area (i.e., a one- 
third wavelength transformation; Fig. 4). To account for the influence of topography on our S-wave velocity models, we subtracted altitude value from the depth value at each grid point. Therefore, the depth shown in our final 3D S-wave velocity models is the depth below sea level (S-wave velocity models before topographic correction are shown in Figures S3, S4 and S5).

\section{Results}

To construct a 3D S-wave velocity structure of the Kinki region, we applied the direct surface wave tomographic inversion using Rayleigh wave dispersion curves. After inverting the dispersion data, we ensured reliability of our measurements by plotting the spatial ray paths coverage in the study area (Fig. 5). From Fig. 5, it is apparent that the ray paths density is sufficient to provide reliable measurements, especially in the innermost part of the study area, where seismic stations are densely distributed. At the edges, however, the ray paths coverage is slightly limited. We further corroborated reliability of our S-wave velocity model by conducting a checkerboard resolution test using anomalies of $\sim 0.2^{\circ}(\sim 22 \mathrm{~km}$; Fig. $6 \mathrm{a}, \mathrm{b})$ and $\sim 0.1^{\circ}(\sim 11 \mathrm{~km}$; Figure S6) for the entire Kinki region and the northern part of the Kinki region, respectively, with an amplitude of the velocity anomaly set to $\sim 10 \%$. In Fig. 6, we display the results of the checkerboard resolution test for horizontal slices at different depths. Using these parameters along with the dispersion measurements, tectonic and geologic features with sizes greater than $10 \mathrm{~km}$ could be observed clearly in the inner part of the study area.

Figure 7 displays selected horizontal slices (map views) at different depths, exhibiting the lateral distribution of S-wave velocities within the study area. The third dimension (depth, in $\mathrm{km}$ ) is given in the numerical form above each horizontal slice. Significant S-wave velocity heterogeneities are apparent and are discussed in the following sections. These anomalies highlight tectonic and geologic features associated with the study area.

Two broad high-velocity anomalies can be observed in the displayed horizontal slices. The first anomaly (marked NM, Fig. 7f) appears to be trending in the $\mathrm{E}-\mathrm{W}$ direction, whereas the second high-velocity anomaly (marked KM) occurs from the southern side of the study area, trending roughly NE-SW across the MTL. These anomalies agree with the results of Nishida et al. (2008), which indicated comparable S-wave velocities in those areas, particularly at a depth of about $2 \mathrm{~km}$ (see Fig. 20 in Nishida et al. 2008). Between the two distinct highvelocity zones exhibited in Nishida et al. (2008), an elongated low-velocity anomaly is evident. Likewise, a prominent low-velocity anomaly is apparent in our results, flanked on both sides by high-velocity zones (NM and KM) and trending roughly NE-SW. Although our results and those of Nishida et al. (2008) at a depth of about 2 $\mathrm{km}$ are similar, our results show prevalent small-scale $(\sim 10 \mathrm{~km})$ low-velocity features at a depth of about $2 \mathrm{~km}$ and shallower. In the work of Nishida et al. (2008), the S-wave velocity model is constrained to a minimum depth of about $2 \mathrm{~km}$ and such narrow low-velocity zones could not be revealed clearly. The higher lateral resolution of our velocity model at shallow depths ( $\leq 2 \mathrm{~km}$ ) than Nishida et al. (2008) model ascribes to the use of shorter wavelength surface waves and the dense seismic array. Most importantly, prominent anomalies identified in our results correlate well with known geologic features, including fault zones, sedimentary basins, and mountain ranges.

\section{Interpretations}

The high S-wave velocity features observed in the northwestern part of the Kinki region (marked NM in Figs. $7 f$ and $9 \mathrm{~b}$ ) are attributable to the presence of the Yakuno intrusive rocks and the Mino/Tamba belts (Fig. 1a). The 
Yakuno intrusive rocks constitute the Maizuru zone, and the Mino/Tamba belts are Jurassic accretionary complexes composed of non-marine sediments, and the extensively distributed granite batholith (Matsushita 1963; Nakae 1993; Nakajima 1994). Moderate-low ray paths coverage towards the edges of the study area compromises the resolution of our S-wave velocity model. However, the extensive low-velocity anomaly labeled NLV in Fig. 7a is attributable to the Neogene volcanic and sedimentary series of the Tango-Tajima terrain (Matsushita 1963). The high velocities on the southeastern side of the study area (around the MTL) may be indicating the presence of the zonally arranged Sanbagawa metamorphic terrain, which consists of the metamorphosed Paleozoic, the Paleozoic and fossiliferous Mesozoic of the Chichibu terrain, and the scanty fossils along with the undivided Mesozoic of the Hidaka terrain (Fig. 1a).

A prominent elongated NE-SW trending low-velocity anomaly occurring between the high-velocity anomalies denoted by NM and KM (Figs. $7 f$ and $9 b$ ) is observed. This low-velocity feature is consistent with the location of the Niigata-Kobe Tectonic Zone (NKTZ, Fig. 1a) and the Biwako-seigan Fault Zone on the western shoreline of Lake Biwa (BSFZ; Figs. 9b and 11a). The BSFZ is constituted of the NNE-SSW-trending west-dipping faults separated by clear small gaps or steps (e.g., the Zeze, Hiei, Katata, Hira, Katsuno, Kamidera, Aibano, and Chinai faults; Fig. 11a), and is reported to have a reverse fault sense of east side subsidence (Takemura et al. 2013). The location of some members of the BSFZ clearly coincide with the low-velocity zone (Lake Biwa) and the highvelocity zone interface in our topography-corrected S-wave velocity models (Hira-Hiei mountains; Fig. 11). On the western side of Mt. Hira, the observed NNE-SSW trending linear low-velocity anomaly is consistent with the location of the right-lateral strike-slip Hanaore Fault (HOF; Fig. 11a), which is suggested to be $\sim 50-\mathrm{km}$-long (Noda and Shimamoto 2009). However, the effects of BSFZ and HOF are not clearly visible in S-wave velocity models without topography correction (Figure S7).

Both the western and eastern sides of the NKTZ are characterized by conspicuous fault systems, with some major faults running through geological units, such as the Yagi-Yabu faults (YGF-YBF) and the Mitoke Fault (MTF) (Mogi et al. 1991). The intervening spaces between fault pairs such as the YGF-YBF and MTF faults are often situated in the terrace and alluvial plain (Katsura 1990). In our results, the low-velocity anomaly observed between the YGF-YBF and the MTF (Fig. 11) probably represent sedimentary units within and around the Fukuchiyama basin (FB), but may also be indicating a possibility of the existence of active faults interconnecting these fault pairs. Besides the gaps between pairs of known active faults, several narrow, elongated low-velocity anomalies are identified, which, to some extent, coincide well with the locations of known active faults. Nonetheless, there are cases where the observed elongated low-velocity anomalies and the locations of known active faults do not correspond (Figs. 10-11). Such elongated low-velocity anomalies are largely trending to the NW-SE and NE-SW directions. We posit that some of these linear low-velocity zones are likely to be attributable to the weathering effects and sediments associated with the activity of undocumented concealed faults or fault zones. On the southern side of the Kinki region, alternating linear low- and high-velocity zones are pronounced (demarcated by a blue curly bracket in Fig. 10b), attributable to the presence of sediments within meridional deep valleys and moutain ranges, respectively (Matsushita 1963).

Distinct low-velocity anomalies occur at the Sanda basin (SB), FB, Osaka basin (OB), Nara basin (NB), Kyoto basin (KB), Oomi basin (OoB), and the Ise basin (IB) (Fig. 9). The OB manifest as a near-elliptical low-velocity zone, with the northern and southern edges of this zone appearing to be oriented ENE-WSW and NE-SW, respectively. The low-velocity values in this area are likely to be representing the Plio-Pleistocene Osaka Group sediments (Itihara et al. 1997). The ENE-WSW trending northern boundary of the OB coincides with the location 
of the Arima-Takatsuki Tectonic Line (ATTL; blue line in Fig. 9a), which is nearly parallel to the MTL (Mitchell et al. 2011). Based on this notion, the ATTL marks the boundary between high-velocity zones (mountainous regions; e.g., the Hokusetsu Mountains) and low-velocity zones (basins; e.g., the SB and OB in Fig. 9a).

According to Hallo et al. (2019), the OB is bounded by two near-parallel reverse faults on its eastern margin, the Uemachi Fault Zone (UFZ) and the lkoma Fault Zone (IFZ). However, the effect of these fault zones is not clear in our results. Even so, our results reveal a low-velocity feature stretching to deeper parts of the displayed vertical sections (Fig. 9c) occurring between known locations of the UFZ and IFZ. This low-velocity anomaly corresponds to a sub-basin of the OB between the elevated areas of Ikoma and Uemachi Upland (Fig. 9c), designated the Kawachi plain (Hatayama et al. 1995). The high-velocity basement material exhibits undulating topographic pattern, with some synclinal parts representing depressional areas in which deep sedimentary basins occur and anticlinal parts corresponding to the basement upheavals or mountain ranges (Figs. 9c-f and $10 c-d)$. Since surface wave inversion is significantly sensitive to the presence of sediments, the low-velocity anomalies observed at depressional areas are postulated to be representing the prevailing thick sediments (Miyamura et al. 1981; Nakayama 1996; Takemura 1985). At the Ise basin (IB, Fig. 9e), the high-velocity material appears to have subsided significantly. This subsidence may be reflecting the effects of the Kuwana and the Yokkaichi reverse faults, which form part of the nearly N-S trending Yoro fault system (Research Group for Active Faults of Japan 1991). Similar discontinuities within the high-velocity material are evident beneath the OB and KB low-velocity material (Fig. 9c-f), likely to be representing the effects of the NKTZ and/or BSFZ.

To assess the seismic activity correlating to the distribution of anomalous zones identified in this study, we superimposed earthquake hypocenters for the period 2001-2012 (Yano et al. 2017) on the S-wave velocity model (Figs. 10a and 11b). Numerous earthquake hypocenters are observed across the high-velocity zone on the western side of Hira mountain (Mt. Hira in Fig. 11b). By contrast, hypocenter clusters are evident on the lowvelocity zone occurring between the Tanba (TA) and Maizuru (MA) tectonic blocks, western part of the HOF and the northern side of ATTL (Figs. 10 and 11). Besides these notable clusters, the northwestern part of the Kinki region has a wide distribution of hypocenters, some of which are aligned in the same trend as elongated lowvelocity zones or along the low- and high-velocity zones interface (Figs. 10a and 11b). Some of the linear lowvelocity zones that do not coincide with known active fault locations but exhibiting chains of earthquake hypocenters (Fig. 11b) may be representing the weathering effects and sediments associated with the activity of undocumented concealed faults or fault zones.

The low-velocity zone along the western part of the Kii Mountainland (blue arrow in Fig. 10a) show a dense distribution of earthquake hypocenters. These conspicuous seismic events are bounded to the north by a near ENE-WSW oriented low-velocity zone, consistent with the location of the MTL. According to Kanamori and Tsumura (1971), increased seismicity on the southern side of the MTL is related to the regional structural heterogeneities associated with the past activity of the MTL, rather than to the local geological structures.

\section{Conclusions}

We used data continuously recorded by a dense seismic array consisting of 221 permanent and temporary seismic stations to estimate a high-resolution shallow 3D S-wave velocity model of the Kinki region. S-wave phase velocity measurements between station pairs were derived using the zero-crossing method in the frequency domain. We then applied a direct surface wave tomographic inversion using high-frequency ambient

Page $10 / 21$ 
noise data $(0.083-0.67 \mathrm{~Hz}$ and $0.05-0.95 \mathrm{~Hz})$. Our results revealed that S-wave velocities vary significantly in the vertical and horizontal directions, which is consistent with the geological heterogeneities of the Kinki region. We attribute the conspicuous high-velocity zones identified in the northwestern and southeastern parts of the study area to the shallow basement material, mountainous regions, or sedimentary complexes. Sedimentary basins manifest as low-velocity zones. Using horizontal and depth slices of the S-wave velocity model, we estimated the locations of the recently reactivated Niigata-Kobe Tectonic Zone and the highly active ArimaTakatsuki Tectonic Line on the northern boundary of the Osaka basin. Also, our results clearly reveal the effects of the active Biwako-seigan Fault Zone on the western coast of Lake Biwa (Fig. 8e-f).

We also identified several fine-scale low-velocity tectonic structures, coexisting with known active faults, such as the N-S-, ENE-WSW-, and NE-SW-trending active faults on the eastern side of the Niigata-Kobe Tectonic Zone. In addition, our results revealed elongated low-velocity features that are not consistent with known active faults, likely to be indicating a possible existence of unidentified faults across the Kinki region. These findings allude to the improved resolution of our S-wave velocity model compared with previous studies of the Kinki region. The observed probable concealed fault zones (linear low-velocity anomalies) characterized by aligned distribution of earthquake hypocenters will be useful for hazard assessment and disaster mitigation. The alternating pattern of subsided and uplifted zones observed in the vertical slices of our S-wave velocity model is consistent with the tectonic history of the Kinki triangle, which has been dominated by the $\mathrm{E}-\mathrm{W}$ compressional movement and has numerous active faults of diverse orientations. These results improve our understanding of shallow crustal structure in the Kinki region. Furthermore, a good correlation between heterogeneities in the S-wave velocity model and the spatial distribution of fault traces and other geologic features in the Kinki region suggests that the approach adopted in this study can be utilized as an effective method for unraveling the complex crustal structure of environments akin to the Kinki region.

\section{Abbreviations}

AF: Aibano Fault; AIST: National Institute of Advanced Industrial Science and Technology; ANT: Ambient Noise Tomography; ATTL: Arima-Takatsuki Tectonic Line; BSFZ: Biwako-seigan Fault Zone; CF: Chinai Fault; CT: Chichibu terrain; EUR: Eurasian; FB: Fukuchiyama basin; HF: Hiei Fault; HiF: Hira Fault; HO: Hokutan Block; HOF: Hanaore Fault; HT: Hidaka terrain; IB: Ise basin; IFZ: Ikoma Fault Zone; JMA: Japan Meteorological Agency; KaF: Katata Fault; KB: Kyoto basin; KF: Kamidera Fault; KtF: Katsuno Fault; KZF: Kizugawa Fault; MA: Maizuru Block; MT: Muro terrain; MTF: Mitoke Fault; MTL: Median Tectonic Line; MZ: Maizuru Zone; NB: Nara basin; NIED: National Research Institute for Earth Science and Disaster Resilience; NKTZ: Niigata-Kobe Tectonic Zone; OB: Osaka basin; OoB: Oomi basin; PHS: Philipine Sea; RAFZ: Rokko Active Fault Zone; RT: Ryoke terrain; SB: Sanda basin; SPAC: Spatial autocorrelation; SKF: Suzuka Fault; SMZ: Sambagawa metamorphic terrain; TA: Tanba Block; TTT: Tango-Tajima terrain; UFZ: Uemachi Fault Zone; YBF: Yabu Fault; YDF: Yamada Fault; YGF: Yagi Fault; YKF: Yokkaichi Fault; YNF: Yanagase Fault; YSF: Yamasaki Fault; ZF: Zeze Fault.

\section{Declarations}

\section{Availability of data and materials}

Continuous seismic waveform data from the Hi-net stations can be obtained from the NIED website (http://www.bosai.go.jp/e/). Continuous seismic data from the Kyushu University station, Tokyo University 
station, Nagoya University stations, AIST stations, Kyoto University stations, JMA stations and Kyoto University Manten project stations are available from the corresponding author on request. The dispersion data used to produce Fig. 3c can be accessed at (https://doi.org/10.6084/m9.figshare.17989979). Our S-wave velocity data is available from this URL (https://doi.org/10.6084/m9.figshare.17138672, Licence CC BY 4.0). Earthquake hypocenters used superimposed on our S-wave velocity models was published by the Japan Unified hlresolution relocated Catalog for Earthquakes (JUICE) project, and can be accessed at this website (https://www.hinet.bosai.go.jp/topics/JUICE/3d/Juice_Hypo3D_Kinki_2001-2012.html; Yano et al. 2017).

\section{Authors' contributions}

BN analyzed the data and drafted the initial manuscript. TT proposed this study. TI, HN, TT suggested the method for data processing and analysis, and revised the manuscript. YI acquired continuous seismic data in and around the Kinki region, and revised the manuscript. All authors contributed significantly to data analysis and interpretation of the results. All authors reviewed and approved the final manuscript.

\section{Competing interests}

The authors declare that they have no competing interests.

\section{Funding}

This work was supported by Japan Society for the Promotion of Science (JSPS) KAKENHI (Grant Numbers JP19K23544, JP20K04133, and JP20H01997).

\section{Acknowledgments}

Seismic data were obtained from the National Research Institute for Earth Science and Disaster Resilience (NIED), the National Institute of Advanced Industrial Science and Technology, the Japan Meteorological Agency, the Disaster Prevention Research Institute of Kyoto University, University of Tokyo, Nagoya University, and Kyushu University. We used a GSpecDisp 1.4 free software package to obtain phase-velocity dispersion measurements, which is made available by Sadeghisorkhani et al. (2018) on this website: (https://github.com/Hamzeh-Sadeghi/GSpecDisp). We utilized a surface wave inversion program to directly invert our dispersion data (DSurfTomo; Fang et al. 2015), which is available from (https://github.com/HongjianFang/DSurfTomo Version 1.3). For data analysis and visualization we used a MATLAB R2020b program. The computations in this work were partly performed using the computer facilities at the Research Institute for Information Technology, Kyushu University. This work was supported by Japan Society for the Promotion of Science (JSPS) KAKENHI (Grant Numbers JP19K23544, JP20K04133, and JP20H01997).

\section{References}

1. Aki K (1957) Space and time spectra of stationary stochastic waves, with special reference to microtremors. Bull Earth Res Ins 35:415-456

2. Anon (n.d.) Geological survey of Japan, AIST. Available from: https://gbank.gsj.jp/subsurface/english/ondemand.php (Accessed 19 November 2021) 
3. Aoki S, lio Y, Katao H et al (2016) Three-dimensional distribution of S wave reflectors in the northern Kinki district, southwestern Japan. Earth Planets Space 68:1-9. https://doi.org/10.1186/s40623-016-0468-3

4. Asano K, Iwata T, Sekiguchi H et al (2017) Surface wave group velocity in the Osaka sedimentary basin, Japan, estimated using ambient noise cross-correlation functions. Earth Planets Space 69:1-20. https://doi.org/10.1186/s40623-017-0694-3

5. Asten MW (2006) On bias and noise in passive seismic data from finite circular array data processed using SPAC methods. Geophysics 71:V153-V162. https://doi.org/10.1190/1.2345054

6. Barnes GL (2008) The making of the Japan Sea and the Japanese Mountains: understanding Japan's volcanism in structural context. Jpn Rev 20:3-52

7. Bensen GD, Ritzwoller MH, Barmin MP et al (2007) Processing seismic ambient noise data to obtain reliable broad-band surface wave dispersion measurements. Geophys J Int 169:1239-1260. https://doi.org/10.1111/j.1365-246X.2007.03374.x

8. Boschi L, Ekström G (2002) New images of the Earth's upper mantle from measurements of surface wave phase velocity anomalies. J Geophys Res Solid Earth 107:1-20. https://doi.org/10.1029/2000JB000059

9. Brown M (2010) Paired metamorphic belts revisited. Gondwana Res 18:46-59. https://doi.org/10.1016/j.gr.2009.11.004

10. Chen KX, Gung Y, Kuo BY, Huang TY (2018) Crustal magmatism and deformation fabrics in northeast Japan revealed by ambient noise tomography. J Geophys Res Solid Earth 123:8891-8906. https://doi.org/10.1029/2017JB015209

11. Cho I, Senna S, Wakai A et al (2021) Basic performance of a spatial autocorrelation method for determining phase velocities of Rayleigh waves from microtremors, with special reference to the zero-crossing method for quick surveys with mobile seismic arrays. Geophys J Int 226:1676-1694.

https://doi.org/10.1093/gji/ggab149

12. Ekström G, Abers GA, Webb SC (2009) Determination of surface-wave phase velocities across USArray from noise and Aki's spectral formulation. Geophys Res Lett 36:5-9. https://doi.org/10.1029/2009GL039131

13. Ekström G (2014) Love and Rayleigh phase-velocity maps, 5-40 s, of the western and central USA from USArray data. Earth Planet Sci Lett 402:42-49. https://doi.org/10.1016/j.epsl.2013.11.022

14. Fang $\mathrm{H}, \mathrm{Yao} \mathrm{H}$, Zhang $\mathrm{H}$ et al (2015) Direct inversion of surface wave dispersion for three-dimensional shallow crustal structure based on ray tracing: methodology and application. Geophys J Int 201:12511263. https://doi.org/10.1093/gji/ggv080

15. Feng M, An M (2010) Lithospheric structure of the Chinese mainland determined from joint inversion of regional and teleseismic Rayleigh-wave group velocities. J Geophys Res Solid Earth 115:1-16. https://doi.org/10.1029/2008JB005787

16. Foti S, Lai CG, Rix GJ, Strobbia C (2014) Surface wave methods for near-surface site characterization. CRC press, Taylor \& Francis Group LLC

17. Gu N, Wang K, Gao J et al (2019) Shallow crustal structure of the Tanlu Fault Zone near Chao Lake in eastern China by direct surface wave tomography from local dense array ambient noise analysis. Pure Appl Geophys 176:1193-1206. https://doi.org/10.1007/s00024-018-2041-4

18. Hallo M, Opršal I, Asano K, Gallovič F (2019) Seismotectonics of the 2018 northern Osaka M6. 1 earthquake and its aftershocks: joint movements on strike-slip and reverse faults in inland Japan. Earth Planets Space 
71:1-21. https://doi.org/10.1186/s40623-019-1016-8

19. Hatayama K, Matsunami K, Iwata T, Irikura K (1995) Basin-induced Love waves in the eastern part of the Osaka basin. J Phys Earth 43:131-155. https://doi.org/10.4294/jpe1952.43.131

20. Hayashi K (2008) Development of surface-wave methods and its application to site investigations, (Doctoral dissertation). Retrieved from Kyoto University Research Information Repository.

(http://hdl.handle.net/2433/57255). Japan: Kyoto University

21. Huzita K (1969) Tectonic development of southwest Japan in the Quaternary period. J Geosci Osaka City Univ 12:53-73

22. Huzita K (1980) Role of the Median Tectonic Line in the Quaternary tectonics of the Japanese Islands. Mem Geol Soc Japan 18:129-153

23. Huzita K, Kishimoto Y, Shiono K (1973) Neotectonics and seismicity in the Kinki area, Southwest Japan. J Geosci Osaka City Univ 16:93-124

24. Hyodo M, Hirahara K (2003) A viscoelastic model of interseismic strain concentration in Niigata-Kobe Tectonic Zone of central Japan. Earth Planets Space 55:667-675. https://doi.org/10.1186/BF03352473

25. lio Y (1996) A possible generating process of the 1995 southern Hyogo Prefecture earthquake: Stick of fault and slip on detachment. Jishin 49:103-112. https://doi.org/10.4294/zisin1948.49.1_103

26. lio Y, Kishimoto S, Nakao S et al (2018) Extremely weak fault planes: an estimate of focal mechanisms from stationary seismic activity in the San'in district, Japan. Tectonophysics 723:136-148.

https://doi.org/10.1016/j.tecto.2017.12.007

27. Itihara M, Yoshikawa S, Kamei T (1997) 24 The Pliocene-Pleistocene boundary in Japan: the Osaka Group. The Pleistocene Boundary and the Beginning of the Quaternary 41:239. https://doi.org/10.1017/CB09780511585760.026

28. Ito K, Umeda Y, Sato H et al (2006) Deep seismic surveys in the Kinki district: Shingu-Maizuru line. Bull Earthquake Res Inst Univ Tokyo 81:239-245

29. Kanamori H (1995) The Kobe (Hyogo-ken Nanbu), Japan, earthquake of January 16, 1995. Seismol Res Lett 66:6-10. https://doi.org/10.1785/gssrl.66.2.6

30. Kanamori H, Tsumura K (1971) Spatial distribution of earthquakes in the Kii peninsula, Japan, south of the Median Tectonic Line. Tectonophysics 12:327-342. https://doi.org/10.1016/0040-1951(71)90020-5

31. Kaneda H, Kinoshita H, Komatsubara T (2008) An 18,000-year record of recurrent folding inferred from sediment slices and cores across a blind segment of the Biwako-seigan fault zone, central Japan. J Geophys Res Solid Earth 113:1-19. https://doi.org/10.1029/2007JB005300

32. Katao H, Maeda N, Hiramatsu Y et al (1997) Detailed mapping of focal mechanisms in/around the 1995 Hyogo-ken Nanbu earthquake rupture zone. J Phys Earth 45:105-119.

https://doi.org/10.4294/jpe1952.45.105

33. Kato A, Ueda T (2019) Source fault model of the 2018 M w 5.6 northern Osaka earthquake, Japan, inferred from the aftershock sequence. Earth Planets Space 71:1-9. https://doi.org/10.1186/s40623-019-0995-9

34. Katoh S, lio Y, Katao H et al (2018) The relationship between S-wave reflectors and deep low-frequency earthquakes in the northern Kinki district, southwestern Japan. Earth Planets Space 70:1-11. https://doi.org/10.1186/s40623-018-0921-6

Page $14 / 21$ 
35. Katsura I (1990) Block structure bounded by active strike-slip faults in the northern part of Kinki district, southwest Japan. Mem Fac Sci Kyoto Univ Ser Geol Mineral 55:57-123. Retrieved from Kyoto University Research Information Repository. (http://hdl.handle.net/2433/186665)

36. Lin FC, Li D, Clayton RW, Hollis D (2013) High-resolution 3D shallow crustal structure in Long Beach, California: Application of ambient noise tomography on a dense seismic array. Geophysics 78:Q45-Q56. https://doi.org/10.1190/geo2012-0453.1

37. Lin FC, Moschetti MP, Ritzwoller MH (2008) Surface wave tomography of the western United States from ambient seismic noise: Rayleigh and Love wave phase velocity maps. Geophys J Int 173:281-298. https://doi.org/10.1111/j.1365-246X.2008.03720.x

38. Matsubara M, Obara K, Kasahara K (2008) Three-dimensional P-and S-wave velocity structures beneath the Japan Islands obtained by high-density seismic stations by seismic tomography. Tectonophysics 454:86103. https://doi.org/10.1016/j.tecto.2008.04.016

39. Matsushita S (1963) Geological history of the Kinki District, Japan during the Cainozoic Era (Preliminary note). Special Contributions of the Geophysical Institute, Kyoto University 2:113-124. Retrieved from Kyoto University Research Information Repository. (http://hdl.handle.net/2433/178442)

40. Matsushita R, Imanishi K (2015) Stress fields in and around metropolitan Osaka, Japan, deduced from microearthquake focal mechanisms. Tectonophysics 642:46-57.

https://doi.org/10.1016/j.tecto.2014.12.011

41. Mitamura M, Matsuyama N, Nakagawa K et al (1994) Stratigraphy and subsurface structure of Holocene deposits around Uemachi Upland in the central Osaka Plain. J Geosci Osaka City Univ 37:183-212

42. Mitchell TM, Ben-Zion Y, Shimamoto T (2011) Pulverized fault rocks and damage asymmetry along the Arima-Takatsuki Tectonic Line, Japan. Earth Planet Sci Lett 308:284-297.

https://doi.org/10.1016/j.epsl.2011.04.023

43. Miyamura M, Yoshida F, Yamada N et al (1981) Geology of the Kameyama district: Quadrangle Series. Geological Survey of Japan 128

44. Mogi T, Katsura I, Nishimura S (1991) Magnetotelluric survey of an active fault system in the northern part of Kinki District, southwest Japan. J Struct Geol 13:235-240. https://doi.org/10.1016/01918141(91)90070-Y

45. Nakae S (1993) Jurassic accretionary complex of the Tamba Terrane, Southwest Japan, and its formative process. J Geosci Osaka City Univ 36:15-70

46. Nakajima T (1994) The Ryoke plutonometamorphic belt: crustal section of the Cretaceous Eurasian continental margin. Lithos 33:51-66. https://doi.org/10.1016/0024-4937(94)90053-1

47. Nakajima J, Hirose F, Hasegawa A (2009) Seismotectonics beneath the Tokyo metropolitan area, Japan: Effect of slab-slab contact and overlap on seismicity. J Geophys Res Solid Earth 114:1-23. https://doi.org/10.1029/2008JB006101

48. Nakayama K (1996) Depositional models for fluvial sediments in an intra-arc basin: an example from the Upper Cenozoic Tokai Group in Japan. Sediment Geol 101:193-211. https://doi.org/10.1016/00370738(95)00065-8

49. Nimiya H, Ikeda T, Tsuji T (2020) Three-Dimensional S Wave Velocity Structure of Central Japan Estimated by Surface-Wave Tomography Using Ambient Noise. J Geophys Res Solid Earth 125:1-18. 
https://doi.org/10.1029/2019JB019043

50. Nishida K, Kawakatsu H, Obara K (2008) Three-dimensional crustal S wave velocity structure in Japan using microseismic data recorded by Hi-net tiltmeters. J Geophys Res Solid Earth 113:1-22.

https://doi.org/10.1029/2007JB005395

51. Nishiwaki H, Okudaira T, Ishii K, Mitamura M (2021) Dip angles of active faults from the surface to the seismogenic zone inferred from a 2D numerical analysis of visco-elasto-plastic models: a case study for the Osaka Plain. Earth Planets Space 73:1-18. https://doi.org/10.1186/s40623-021-01390-8

52. Noda H, Shimamoto T (2009) Constitutive properties of clayey fault gouge from the Hanaore fault zone, southwest Japan. J Geophys Res Solid Earth 1141-1129. https://doi.org/10.1029/2008JB005683

53. Obara K, Kasahara K, Hori S, Okada Y (2005) A densely distributed high-sensitivity seismograph network in Japan: Hi-net by National Research Institute for Earth Science and DisasterPrevention. Rev Sci Instrum 76:021301. https://doi.org/10.1063/1.1854197

54. Oike K (1976) Spatial and temporal distribution of micro-earthquakes and active faults. Mem Geol Soc Japan 12:59-73

55. Pilz M, Parolai S, Picozzi M, Bindi D (2012) Three-dimensional shear wave velocity imaging by ambient seismic noise tomography. Geophys J Int 189:501-512. https://doi.org/10.1111/j.1365-246X.2011.05340.x

56. Rawlinson N, Sambridge M (2004) Wave front evolution in strongly heterogeneous layered media using the fast marching method. Geophys J Int 156:631-647. https://doi.org/10.1111/j.1365-246X.2004.02153.x

57. Research Group for Active Faults of Japan (1991) Active faults in Japan: Sheet maps and inventories. University of Tokyo press, p 437

58. Sabra KG, Gerstoft P, Roux P (2005) Surface wave tomography from microseisms in Southern California. Geophys Res Lett 32:1-4. https://doi.org/10.1029/2005gl023155

59. Sadeghisorkhani H, Gudmundsson Ó, Tryggvason A (2018) GSpecDisp: A matlab GUl package for phasevelocity dispersion measurements from ambient-noise correlations. Comput Geosci 110:41-53. https://doi.org/10.1016/j.cageo.2017.09.006

60. Sagiya T, Miyazaki SI, Tada T (2000) Continuous GPS array and present-day crustal deformation of Japan. Pure Appl Geophys 157:2303-2322. https://doi.org/10.1007/PL00022507

61. Sato H, Ito K, Abe S et al (2009) Deep seismic reflection profiling across active reverse faults in the Kinki Triangle, central Japan. Tectonophysics 472:86-94. https://doi.org/10.1016/j.tecto.2008.06.014

62. Shapiro NM, Campillo M, Stehly L, Ritzwoller MH (2005) High-resolution surface-wave tomography from ambient seismic noise. Science 307:1615-1618. https://doi.org/10.1126/science.1108339

63. Shapiro NM, Ritzwoller MH (2002) Monte-Carlo inversion for a global shear-velocity model of the crust and upper mantle. Geophys J Int 151:88-105. https://doi.org/10.1046/j.1365-246X.2002.01742.x

64. Suemoto Y, Ikeda T, Tsuji T, lio Y (2020) Identification of a nascent tectonic boundary in the San-in area, southwest Japan, using a 3D S-wave velocity structure obtained by ambient noise surface wave tomography. Earth Planets Space 72:1-13. https://doi.org/10.1186/s40623-020-1139-y

65. Taira A (2001) Tectonic evolution of the Japanese island arc system. Annu Rev Earth Planet Sci 29:109134. https://doi.org/10.1146/annurev.earth.29.1.109

66. Takemura K (1985) The Plio-Pleistocene Tokai Group and the tectonic development around Ise Bay of central Japan since Pliocene. Mem Fac Sci Kyoto Univ Ser Geol Mineral 51:21-96. Retrieved from Kyoto 
University Research Information Repository. (http://hdl.handle.net/2433/186655)

67. Takemura K, Haraguchi T, Kusumoto S, Itoh Y (2013) Tectonic basin formation in and around Lake Biwa, Central Japan. Mechan Sedim Basin Form 9:209-229. https://doi.org/10.5772/56667

68. Tsai VC, Moschetti MP (2010) An explicit relationship between time-domain noise correlation and spatial autocorrelation (SPAC) results. Geophys J Int 182:454-460. https://doi.org/10.1111/j.1365-

246X.2010.04633.X

69. Usami T (2003) Materials for comprehensive list of destructive earthquakes in Japan. Univ. of Tokyo Press, Tokyo, p 605

70. Wakita K (2013) Geology and tectonics of Japanese islands: a review-the key to understanding the geology of Asia. J Asian Earth Sci 72:75-87. https://doi.org/10.1016/j.jseaes.2012.04.014

71. Yang Y (2014) Application of teleseismic long-period surface waves from ambient noise in regional surface wave tomography: a case study in western USA. Geophys J Int 198:1644-1652. https://doi.org/10.1093/gji/ggu234

72. Yano TE, Takeda T, Matsubara M, Shiomi K (2017) Japan unified high-resolution relocated catalog for earthquakes (JUICE): crustal seismicity beneath the Japanese Islands. Tectonophysics 702:19-28. https://doi.org/10.1016/j.tecto.2017.02.017

73. Yao H, van Der Hilst RD, De Hoop MV (2006) Surface-wave array tomography in SE Tibet from ambient seismic noise and two-station analysis-I. Phase velocity maps. Geophys J Int 166:732-744. https://doi.org/10.1111/j.1365-246X.2006.03028.x

74. Yao H, Beghein C, Van Der Hilst RD (2008) Surface wave array tomography in SE Tibet from ambient seismic noise and two-station analysis-II. Crustal and upper-mantle structure. Geophys J Int 173:205-219. https://doi.org/10.1111/j.1365-246X.2007.03696.x

75. Yolsal-Cevikbilen S, Biryol CB, Beck S et al (2012) 3-D crustal structure along the North Anatolian Fault Zone in north-central Anatolia revealed by local earthquake tomography. Geophys J Int 188:819-849. https://doi.org/10.1111/j.1365-246X.2011.05313.x

\section{Figures}

\section{Figure 1}

a Map of the Kinki region showing the spatial distribution of tectonic structures. Red lines represent active faults (retrieved on 19 November 2021 from https://gbank.gsj.jp/subsurface/english/ondemand.php), thick purple, yellow, and light blue lines represent the Niigata-Kobe Tectonic Zone (NKTZ), Rokko Active Fault Zone (RAFZ), and the Arima-Takatsuki Tectonic Line (ATTL), respectively. Also shown are the locations of the Median Tectonic Line (MTL), and tectonic divisions of the Kinki region, comprising Tango-Tajima Terrain (TTT), Maizuru Zone (MZ), Mino-Tamba Terrain (MTT), Ryoke Terrain (RT), Sanbagawa Metamorphic Zone (SMZ), Chichibu Terrain (CT), Hidaka Terrain (HT), and Muro Terrain (MT). The insert shows the location of the Kinki region within Japan. b Topographic map of the Kinki region. Black and red triangles indicate the locations of permanent and 
temporary stations, respectively. White, broken lines indicate the boundaries between the Northwestern Mountainland, Central Lowland, and Kii Mountainland.

\section{Figure 2}

Cross-correlation functions showing the empirical Green's functions between station pairs for frequencies ranging from 0.05 to $0.95 \mathrm{~Hz}$. a Cross-correlation function for a station pair with an interstation distance of 57.18 km (shown in Fig. 3b), and b stacked cross-correlation functions from randomly selected station pairs, exhibiting Rayleigh wave propagation between paired seismic stations.

\section{Figure 3}

a Observed phase velocity dispersion curves (upper panel) and the real part of the cross-correlation spectrum (lower panel). Red and black circles in the upper panel represent the selected points of the dispersion curve and the average phase-velocity dispersion curve for the region, respectively. $\mathbf{b}$ Location of the station pair for which dispersion data are displayed in a. c Phase-velocity-frequency plot showing the 23,647 selected dispersion curves for all the station pairs used.

\section{Figure 4}

The initial S-wave velocity model used as a reference in the inversion process. The blue line and blue dots represent the average S-wave velocity model. The black dots represent all the interstation Rayleigh wave phasevelocity dispersion curves measured using the zero-crossing method transformed to a depth-S-wave velocity approximation.

\section{Figure 5}

Ray paths derived from the inversion model at two selected frequencies: a $0.5 \mathrm{~Hz}$ and $\mathbf{b} 0.2 \mathrm{~Hz}$. Also shown are the locations of permanent seismic stations (black triangles) and temporary seismic stations (red triangles). Blue lines indicate ray paths. 


\section{Figure 6}

Horizontal velocity perturbation slices of the checkerboard resolution test results at $1 \mathrm{~km}$ a and $2.2 \mathrm{~km} \mathbf{b}$ depths. The anomaly size was $\sim 22 \mathrm{~km}\left(0.2^{\circ}\right)$, and the velocity amplitude was $\sim 10 \%$. Depth is shown above each horizontal slice.

\section{Figure 7}

Horizontal slices of the S-wave velocity model at discrete depth levels below sea level. Depth is shown above each respective panel. $\mathbf{a}-\mathbf{f} \mathbf{S}$-wave velocity models without showing the active faults (S-wave velocity models before correcting for the effects of topography are shown in Figure S4). NM and KM represent the prominent high-velocity anomalies.

\section{Figure 8}

Horizontal slices of the S-wave velocity model at discrete depth levels below sea level. a-d S-wave velocity models overlaid with active faults (black lines). Depth is shown above each respective panel. Also shown is the location of the Median Tectonic Line (MTL).

\section{Figure 9}

S-wave velocity structure at $0.9 \mathrm{~km}$ a and $2 \mathrm{~km}$ b depths below sea level, and vertical slices $\mathbf{c}-\mathbf{f}$ vertical S-wave velocity sections beneath the profiles marked in a, showing the variation of S-wave velocity with depth (bottom panels) and their respective elevation models in $\mathrm{km}$ (top panels). The solid black line represents the Median Tectonic Line (MTL), the dashed red closed-curve represents the Niigata-Kobe Tectonic Zone (NKTZ), and the thick solid blue line indicates the location of the Arima-Takatsuki Tectonic Line (ATTL). The gray-shaded area represents the Kinki triangle. Black triangle represents the location of Hokusetsu mountains. Thin, dashed black closed-curves show the locations of major sedimentary basins (SB, Sanda basin; FB, Fukuchiyama basin; OB, Osaka basin; NB, Nara basin; OoB, Oomi basin; KB, Kyoto basin; and IB, Ise basin). Also shown on the depth slices are the probable locations of the Kawachi plain, Nara basin (NB), Uemachi Fault Zone (UFZ), Ikoma Fault Zone (IFZ), Biwako-seigan Fault Zone (BSFZ), NKTZ, Osaka basin (OB), and Ise basin (IB). 


\section{Figure 10}

a Map of seismic events that occurred during the January 2001 to December 2012 period (Yano et al. 2017) superimposed on the S-wave velocity model horizontal slice at $0.6 \mathrm{~km}$ depth below sea level. Plotted hypocenters (black dots) are for earthquakes ranging from 0 to 6.5 in moment magnitude for depths shallower than $12 \mathrm{~km}$. Blue arrow indicates the location of dense distribution of earthquake hypocenters along the western part of the Kii Mountainland. b Distribution of active faults superimposed on the S-wave velocity model horizontal slice at $0.6 \mathrm{~km}$ depth below sea level. Solid black lines represent active faults documented before this study was conducted (Research Group for Active Faults of Japan 1991). Thick dashed white closed-curve and a solid green line indicate the locations of the Niigata-Kobe Tectonic Zone (NKTZ) and the Arima-Takatsuki Tectonic Line (ATTL), respectively. Also shown are the locations of the Median Tectonic Line (MTL), Yamada Fault (YDF), Yamasaki Fault (YSF), Jumantsuji Fault (JMF, a member of the ATTL), Yabu Fault (YBF), Yagi Fault (YGF), Mitoke Fault (MTF), Hanaori Fault (HOF), Kizugawa Fault (KZF), Suzuka Fault (SKF), Yokkaichi Fault (YKF), Yanagase Fault (YNF), Uemachi Fault Zone (UFZ), Ikoma Fault Zone (IFZ), Tanba Block (TA), Hokutan Block ( $\mathrm{HO})$, and the Maizuru Block (MA). Blue curly bracket marks the location of three alternating meridional deep valleys and mountain ranges. $c-f$ Vertical sections showing the S-wave velocity variation beneath the profiles marked as solid magenta lines in Fig. 9b. Inferred locations of the Kyoto basin (KB), Ise basin (IB), Lake Biwa and the Biwako-seigan Fault Zone (BSFZ) and/or Niigata-Kobe Tectonic Line (NKTZ) along the profile are also shown on the vertical sections.

\section{Figure 11}

a Enlarged view of the northern part of the Kinki region (shown in Fig. 9) showing the perturbation of S-wave velocity at a depth of $0.5 \mathrm{~km}$ below sea level. Also shown are the locations of the Yamada Fault (YDF), Yamasaki Fault (YSF), Yagi-Yabu Fault (YGF-YBF), Mitoke Fault (MTF), Hanaore Fault (HOF) and the Biwakoseigan Fault Zone members (Chinai Fault, CF; Aibano Fault, AF; Kamidera Fault, KF; Katsuno Fault, KtF; Hira Fault, HiF; Katata Fault, KaF; Hiei Fault, HF; Zeze Fault, ZF) (Kaneda et al. 2008). b perturbation of S-wave velocity at a depth of $1 \mathrm{~km}$ below sea level, overlaid with earthquake hypocenters (black dots; Yano et al. 2017) and active faults. Black triangles represent the Hira and Hiei mountains. Solid black lines show the location of documented active faults (Research Group for Active Faults of Japan 1991).

\section{Supplementary Files}

This is a list of supplementary files associated with this preprint. Click to download. 
- EPSNthabaGRAPHICALABSTRACT250122.jpg

- EPSNthabaSuppInfo250122.docx 